\title{
MIGRATION IN CONTEMPORARY SECURITY ENVIRONMENT
}

\author{
Zoran DRAGIŠIĆ, PhD \\ Faculty of Security Studies, University of Belgrade \\ E-mail:dragisicz@yahoo.com \\ Milica ĆURĆIĆ, PhD Candidate \\ Faculty of Security Studies, University of Belgrade \\ E-mail: milicacurcic@hotmail.com
}

\begin{abstract}
Contemporary security environment has been facing with a numerous security threats: from old threats to new and transformed threats. Security is no longer associated with pure military force that threaten the stability or the typical function of states. The broadening and deepening of our understanding of what constitutes a security threat and challenge has resulted with new areas of so called new security agenda. According to new security agenda, migration becomes one of main security threat to the national and human security. Migration is a complex social phenomenon caused by a different reasons: economics, social, political, religious and cultural. The perception of migration as a threat to security in European security policy has developed alongside with the rapid increase in the number of migrants, especially from the Middle East and North African countries. The concept of social security primarily deals with the issue of collective identity. Immigration of people of other culture, ethics, religions, habit and customs can be perceived as a threat to the identity and the way of life in the local population. Migration can pose a threat to a state's national interest through its impact on the state's economy and become a threat to economic security of state. Also, migration can come in conjunction with other security threats. So, mass migrations can pose a serious security threat because of the role that organized crime plays in guiding and directing refugee waves, as well as the possibility for terrorists to use migration waves to destabilize European countries. The aim of this paper is to explore in which cases migration can justifiably be considered as a security problem, then which implications in term of low, policies and procedures labelling of migration as a security threat has. At that way we analyze how the Balkans and Europe countries deal with migration as a security issue. A special focus is on researching the connection between migration, organized crime and terrorism.
\end{abstract}

Keywords: migration, security threat, security environment, organized crime, terrorism

\section{Introduction}

The contemporary security environment is characterized by the emergence of a new nonstate actors, a new and transformed security threats, with the prominent role of the factors of globalization and usage of sophisticated technologies. There are numerous attempts to concep- 


\section{Securitity}

tualize the growing complexity of actors, i.e. to codify a new security threats that are incompatible with the traditional categorization of security threat in order to security theory provide a good response to the changed security reality. One of numerous phenomena that has received a character of security threat is migration.

Migration of the population is not a new social phenomenon, they are an integral part of human existence. Whether single or in group, migration is a constant companion of social development. However, not all migrations are also a security threat. Migration can be seen as a welcome mix of the population that brings a new cultural and civilization quality and a process that opens the possibility for more intensive economic development. So it is important to analyze and understand which migration can justifiably be considered a security issue, and under which circumstances this may be the case.

The perception of migration as a threat to national security has certainly heightened in recent years, in part as the security agenda has become more prevalent across many aspects of policy, and in part in response to the rapid rise in the number of international migrants or and their real and imagined connection to terrorism, organized crime and other dangerous that society deals with. The phenomenon of a large number of migrants who came to Europe from the Middle East and North Africa brought the migration to the very top of the security agenda of most European countries. It is a very challenging and difficult task that is given to countries which need to find political responses to this problem which would make the fate of the migrants more certain, and the populations of the countries where they migrated provided guarantees that immigrants would not jeopardize their safety or impair their lifestyle.

One of the most visible consequences of the broad geopolitical re-composition of the North African and Middle East areas that begin with the "Arab spring" in 2011 have been the migrant crisis. The rise in violence, the eruption of political conflicts in a series of wars, as well as the fragmentation and destabilization of the states in this area have led to an increase in migration towards North and North-West Europe as a safe zone. The movement of refugee columns from Syria to the surrounding Middle Eastern countries is clear visible consequences of avoiding war and running away from military operations and war destruction. The logic of migrating people from the Middle East and North Africa towards Europe is, however, completely different: people driven by the destabilizing "Arab Spring" are motivated primarily by economic reasons and their movement towards Europe has a completely different geopolitical dimension than that related to the wars caused by the "Arab Spring".

The migration of people from the North African and Middle East have a great implication on different area of life states of origin, transit and destination states. Also, migration is dynamic social phenomenon and their causes, manifestations, scope, directions will change and therefore the effects on human, national and international security. For this reason, the research into the impact of migration on the contemporary security environment should be multidisciplinary and systematic. 


\section{Understanding the phenomenon of modern migration}

Numerous scientific areas deal with migration research and understanding of migration depends on scientific field of theoretical and practical research. The study of the phenomenon of contemporary mass migrations and the fate of migrants at the place of their arrival in contemporary social research is predominantly directed to normative, demographic, cultural, economic, psychological, geopolitical researches. The complexity of the phenomenon of migration and multidisciplinary of its study makes it almost impossible to find a commonly accepted explanation for this phenomenon. We suggest that special attention should be focused on the security approach of migration studies that needs to have multidisciplinary character in order to investigate all the significant characteristics of this phenomenon.

The normative approach to migration can be seen mainly from two different, but complementary angles:

- The principles and standards deriving from State sovereignty. These include the right to protect borders, to confer nationality, to admit and expel foreigners, to combat trafficking and smuggling and to safeguard national security;

- The human rights of the persons involved in migration. Many relevant conventions exist at the universal and regional levels, although most of them do not explicitly refer to migrants or recognize them as a specific group. These instruments are spread across various branches of law, such as human rights law, humanitarian law, refugee law, criminal law and labour law; the relevant human rights norms are therefore dispersed throughout a wide range of texts (About Migration Law - IOM).

So, this approach identify the major considerations that should be taken into account in formulating migration policies, analyze normative implication on migration and international and national migration norms.

The demographic approach to migration is referred to examination the impact of migration on demographic development: on fertility, mortality population structure and average age of population. Population aging and low fertility have an important role in the development of European society and economy, which is why all European countries implement or prepare policy measures to adapt to this changes. Immigration in Europe brings younger, working-age population with its potential can reduce and mitigate the demographic effects of aging and low fertility. Young, working-age population is the preferred category of immigrants in all countries with a developed economy and unfavorable demographic trends (Arsenovic, 2017: 192).

The economic approach to migration is focused on three related issues:

1. what determines the size and skill composition of immigrant flows to any particular host country

2. how do the immigrants adapt to the host economy

3. what is the impact of immigrants on the host country's economy (Borjas, 1989:457) 
Basically, this approach on the economic aspects of integrating part of the working-age immigrant population and the costs of their support within a kind of cost-benefit analysis.

The cultural approach to migration is based on understanding that arrival of large numbers of migrants from very different social or cultural backgrounds than the receiving communities represent a challenge to social cohesion. So, this approach should explore and present numerous aspects of sociocultural ambitions of societies that migrant have left and those in which they come. Also, there are necessity to understand implications of modern migration regarding models of integration and national identity. The promotion of a multiculturalism, fostering the concept of cultural diversity as a part of cultural identity, understanding other cultural patterns are just some of the aspects that this approach affirms.

The geopolitical approach to migration is focused on geopolitical dimensions of the cause of migration and its geopolitical consequences. In the geopolitics research, the great significance is attached to political and demographic factor. The quantitative and qualitative characteristics of the population have a great significance for understanding the spatial-political relations. In analysis of the geopolitical aspects of migration, it is necessary to make a differentiation between the causes of migration and its consequences. Understanding the causes of migration through the prism of geopolitics can create conditions for perception of problems, finding answers and taking practical measures in finding solutions (Stepic, 2016:22). This approach is also focused on exploration of the geopolitical turmoil where the cause is arrival of migrants in certain areas, which brings with it new cultures, languages, values, habits and religions.

The psychological approach to migration analyze psychological aspect of behavior of migrant and domestic people. Also, it research on how psychology can contribute to understanding the current "migration crisis". It recognizes three important ways on which psychology can provide insights into:

1. How successive generations of forced migrants adjust to receiving cultures (and vice versa). In the context of migration, this concept can help us to understand the early stages of 'culture shock'. Psychological research suggests that there are four different acculturation strategies: assimilation (when a migrant adopts the receiving culture and rejects their original culture), separation (when a migrant rejects the receiving culture and maintains their original culture), integration (where a migrant both adopts the receiving culture and maintains their original culture), and marginalization (where a migrant rejects the receiving culture and rejects their original culture);

2. The anger and hostility that is directed to migrants. Much of the anger and hostility that is directed toward migrants is related to feelings of threat (and specifically economic threat). The hostility that many people feel towards migrants can be shown to be related to their own feelings of economic vulnerability.

3. How individuals, social services, and government can build capacity to bring about positive outcomes for migrants and receiving societies. Psychological research shows that integration is the most positive form of acculturation. Successful integration requires 


\section{Security}

a) Opportunities to meet members of the receiving culture and build positive relationships with them and

b) Support networks to maintain cultural ties (A Psychological Perspective on the Current "Migration Crisis").

The security approach to migration implies a multidisciplinary approach that use the knowledge of previous approaches in order to determine, in a common way, the cause and consequences of migration, through the prism of security. Firstly, security approach need to distinguish a different form of human movement and to determine a differences among them. Security consequences aren't produced by every human movement. The movement of population from village to city within the same state is significant demographic, social and economic issues, but does not produce significant consequences for the security of the state and citizens. Also, it is necessary to research the real causes of migration, is that some kind of armed conflict, deprivation of human rights etc. and what causes that situation. Analysis of consequences of migration should include a different areas of social life - from political, economic, demographic, cultural, psychological etc. in order to understand the complexity of security reality.

It is necessary to be very cautious in the categorization of migration as a security threat. Labeling migration as security threat has significant implications in terms of the laws, norms, policies, and procedures that become justified in response. So, the label that some migration is security threat can be used to justify greater surveillance, detention, deportation and more restrictive policies. In that case, we are talking within the framework of securitization of migrations.

Key security issues related to migration are in context of organization of migration (spontaneous or organized), their legality (legal or illegal) and ultimate goals that should be accomplished by the massive moving of the population.

\section{Immigration security dilemma}

Within the academic field of security studies, it has been argued, that there has been "a tectonic conceptual shift in immigration research... since the late 1980's, with a disproportionately large and growing number of studies framing migration as a security issue" (Alexseev, 2006:6). Real or imagined links to terrorism, organized crime and health threats are at the core of the perception of migration as a security threat. Surely, security concerns of this kind must be taken seriously and migration management and border management policies designed to respond are needed, but only if migration represent a real security threat.

The duality of threats apparently caused by migration to both national sovereignty and human security are largely reflected in much of the recent academic literature. Approaches to migration as a security issue vary considerably depending on who or what is considered to be threatened (Thompson, 2013). Those discussion are in the context of whose security-state or humans question. 
Migration as a security issue has remained largely peripheral to traditional International Relations approaches, such as neo-realism, which focuses on the security of the nation state in an anarchical international system and regards security issues largely as external military threats from other states. However, some within the field have adopted a state-centric position to the issue of migration and security and are closely aligned with traditional realist International Relations theory, but acknowledge that non-state actors, in this case migrants or at least certain categories of migrants, can pose a threat to the autonomy, sovereignty, and territorial integrity of the state with the potential ability to cause disputes or even conflict between countries (Thompson, 2013). According to the argument, states have a sovereign right to control who crosses their borders, and that by undermining that control illegal migrants therefore threaten sovereignty. In this perception states are on risk being 'flooded' or overwhelmed by enormous numbers of irregular migrants. Those migrants can threaten economic stability by increasing employment competition, undermine social stability where it is combined with the rise of xenophobia and lack of integration, and be associated with multiple challenges associated with increasing religious, cultural and ethnic heterogeneity. Also, those migrants can be associated with criminal activities - on the part of migrant smugglers and human traffickers, and also migrants themselves who engage in 'survival crimes'. At the end, they can be associated with terrorist organization. So, national security perspective, or a state-centric approach to migration focuses on border management challenges that may undermine a state's sovereignty as well as migration's real or imagined threats to the population of countries of destination.

A variation on this 'state-centric' approach was introduced via the securitization framework given by Copenhagen School. Studies that place the state or society as the referent object of security have often sought to establish or contest the levels of threat manifested by the range of pernicious activities that migrants are frequently accused of. The discursive representation of migration into a security issue plays an equally important role in the logic of securitisation. In the last years populist discourses have depicted migrants as those who invading borders, burdening health, education, welfare and social services, endangering health, escalating crime, generating unemployment amongst the local workforce by competing for jobs and causing wage deflation, placing additional strains on housing and jeopardizing the language, culture and social values of host societies as well as transnational issues such as human trafficking and terrorism. Such discourses have entrenched a binary perspective separating the citizen from the migrant or the other.

Restrictive policies and security-oriented discourses can consolidate the migration question into a national and societal threat, one that has high priority in agenda-setting and public debates. The construction of the migration question into a security threat not only bodes ill for refugee protection but also for the stability of hosting states. In several European states, the 'security-laden' migration question has fueled domestic tensions between parties and platforms, encouraging solidarity with refugees and those calling for prioritizing states' obligations towards its own citizens and closing its borders (Fakhoury, 2016:11). 
An alternative approach to migration as a security issue has been to place the migrant as the referent object of threats and assess the human security aspects of migration. The structural violence that causes many to migrate, the impact of deportation and detention policies and the hazards to personal safety of migrants resulting from the increasing reluctance of states to offer sanctuary to those genuinely in need are just some of the aspects of the nexus between migration and human security (Thompson, 2013). The aspect of human security is oriented on research of adverse consequences for migrants themselves whether they ran away from conflict, become the victims of trafficking, or become a victim of other ways of abuse of their human rights - they can be afflicted by infectious disease, poor nutrition, inaccessibility of healthcare; and fight personal security threats including violence, incarceration in transit countries and admission countries, restriction of freedom of movement and restriction of the right to work.

As Kerwin $(2016$, п. 3) noticed, human security is often set against the concept of national security, but the two need not be at odds. Properly crafted national security policies should further human security. However, the human security frame moves the migration discussion beyond national security's narrow preoccupation with border control, detention, and the criminalization of migrants, and opens it to the conditions of insecurity that drive irregular and crisis migration. Human security also asks whether policies developed out of a misguided view of national security put people in less secure positions, like the hands of traffickers and smugglers.

Another aspect of the ongoing debate is that work on the migration-security nexus focuses to a large degree on security challenges to developed countries as countries of destination, and a number of scholars point to the fact that the impact on developing countries as countries of destination but also of transit and of origin is neglected (Wohlfeld, 2015:70). These approach represents a variant of a state-centric approach, and it is in context of 'security of which state' question. Migration movements have the impact on social, economic and security situation not only of the countries of destination, but also on the countries of origin and transit. That creates the need on broader policies aimed at addressing the security-migration nexus to reconciliation the positions of developed countries of destination and origin and transit countries.

\section{Characteristics of modern migration}

At its simplest, migration can be understood as the movement of people from one place to another. The International Organization for Migration (IOM) defines migration as "The movement of a person or a group of persons, either across an international border, or within a State. It is a population movement, encompassing any kind of movement of people, whatever its length, composition and causes; it includes migration of refugees, displaced persons, economic migrants, and persons moving for other purposes, including family reunification" (IOM-Key Migration Terms). The reality is that majority of migrants migrate in search of work and economic and social opportunities, and a relatively small percentage of migrants are people fleeing armed conflict, human rights abuse, natural disaster, famine or persecution.

There are numerous categorizations of migraines, depending on the aspects that are in the focus of the researcher attention. One of the most common division of migrations in is based on 
the legal status of international migrants and it can be legal and illegal. The necessary condition for illegal migration is that a person has moved beyond the legal frameworks of the countries of origin or destination, or that it violated the legal norms of the transit countries if they existed. So, as legal migrants we recognize those who have been granted temporary residence permits in the territory of the state, while illegal migrants represent foreign nationals who illegally entered the territory of the state (illegal entry outside the border crossing or entry with forged documents) or those who legally entered but after the expiration of the temporary residence permit they are not left the territory of the state. Also, it is used a term irregular migrant, as a synonym for illegal migrant. IOM defines irregular migration as "Movement that takes place outside the regulatory norms of the sending, transit and receiving countries. There is no clear or universally accepted definition of irregular migration. From the perspective of destination countries it is entry, stay or work in a country without the necessary authorization or documents required under immigration regulations. From the perspective of the sending country, the irregularity is for example seen in cases in which a person crosses an international boundary without a valid passport or travel document or does not fulfil the administrative requirements for leaving the country. There is, however, a tendency to restrict the use of the term "illegal migration" to cases of smuggling of migrants and trafficking in persons" (IOM-Key Migration Terms).

In the demographic theory, migration is divided according to a number of criteria (in relation to the state border, relative to the time, relative to the cause, etc.). However, the voluntarism and organization of migrations represent, from a security aspect, the only relevant criteria for the division of migrations. The right of people to move freely is one of the basic human rights protected by international human rights instruments. The Universal Declaration of Human Rights in Article 13 guarantees freedom of movement and free choice of residence. The right to freedom of movement also includes the right of a person to leave any state, including the one whose citizen is, and to return freely to it. The right to freedom of movement may be restricted solely for reasons provided for by the laws of the States. International law, as well as national legislation, recognize different categories of migrants and, depending on the category to which migrants are attached, provide adequate legal protection.

Migrants form a very heterogeneous group and they can be divided into two large groups on the basis of the criteria of voluntary abandonment of their former residence. In a group that voluntarily, or without physical force, leaves its previous place of residence are foreigners who reside in the territory of country where they don't have citizenship. The basic characteristic of this group of migrants is that they can return to the country of their origin without fear of murder, persecution or other inhuman acts. The most frequent category of voluntary migrants are foreign workers, then people who reside in the territory of the country for marriage, education, longer health treatment or any other reason that the immigration country accepts as justified for granting licenses for legal residence of foreigners on their territory (Dragisic, 2015: 371-372).

Various factors affect the individual to decide to leave the home country, and most often they are classified into the following groups: 
1. Economic factors - the growing gap between living standards and personal income attracts migrants to countries with higher living standards, economic development, and with better chance to find a job;

2. Conflicts - conflicts can, by their nature, be ethnically and/or religious, but also a result of economic inequalities or racing for natural resources. Also, the lack of personal and religious freedoms can be motivational factor, as well as discrimination against race, gender, religion or other basis;

3. Demographic disproportion - it can have different forms of manifestation - from the negative fertility in developed countries and the prolongation of the average length of life, which contributes to the discrepancy between the supply and demand of labour in developed countries. A surplus labour in the underdeveloped can create an increase in the unemployment rate, which is a motivational factor for migration. On the other hand, the increasingly elderly population in developed countries increasingly shows the need for foreign labor to fill the shortage of the labor-efficient population. Many countries had a positive natural increase only after the arrival of a large number of immigrants;

4. Government and public services - the poor government and health care, corruption and lack of quality education can strengthen the process of migration to other countries;

5. Environmental factors - An increasing number of people are deciding to migrate due to industrial accidents, floods, soil erosion, earthquakes, and effects of climate change, increased radioactivity, infectious diseases and similar causes. However, most migrants from this group is retained within the home country;

6. Transnational communication networks - they are organized by emigrant communities in the countries of the final migration destinations and they can form social and cultural patterns for potential emigrants. Thus, members of a communication network or family abroad can promote migration and manage migration processes for third-party accounts, such as the migration in industrial highly developed countries (Blagojevic, Milosavljevic, 2016: 82).

Authors point out that the number of irregular migrants have been growing as a result of several trends. The first one is increased mobility as a result of globalization, and advances in transport and communications, and indeed also the general growth of migration. The second one is the increasing limitation of legal migration possibilities, as governments respond by restrictions. The third is that there is substantial mismatch between the supply and demand sides for labour. And the fourth is that cases of mass migration often result from mass infringements of human rights and conflict, such as is the case in Syria, Libya, Iraq or the Middle East (Wohlfeld, 2015: 66-67).

When it comes to the characteristics of migrants who migrate from the Middle East to Europe, migrant shows a great knowledge about routes of migration and react almost immediately to their changes; they are well-coordinated and quite familiar with the opportunities in the countries they are moving; they have enough money (not only cash, they already raise donated money by credit cards, etc.), they are persistent in reaching targeted destinations - some of the most developed EU countries, and not those with a somewhat lower standard. Financial support to make a long and difficult journey is obtained not only from relatives who already live in the 
EU, but above all by the Gulf monarchies that previously had supported the insurrection that destroyed their homeland, the same countries that showed no interest in receiving and registering refugees although they belong to some of the most important petrodollar states (Gajic, 2016: 88).

Migrants move along the eight main routes - the route to the center of Europe: the West-African route, the West-Mediterranean route (from the Maghreb to Spain and France), the Central-Mediterranean route (from the Libyan and Tunisian coasts to the Apennine Peninsula), rotate through Apulia and Calabria, the Balkan route (from Greece, via Macedonia and Serbia to Hungary and Croatia), the east-Mediterranean route (overseas routes from Levant to Greek islands, then, to the Balkans) and (the smallest) route through the eastern borders of the EU (from the post-Soviet space) to its central lands. The most important routes are, of course, the Central-Mediterranean and Balkan routes which point to the porosity of the European maritime border and the unintegrated part of the Balkans (Gajic, 2017:15-16).

It has been noticed that during a certain period of time refugees in Serbia came in daily defined quotas in organized groups, with a clear plan for further travel. All this leads to the conclusion that this is a good organizational activity. In addition, the way in which they are financed, communicated and changed plans when there are unforeseen circumstances leads to the conclusion that there is a mass organization in charge which comes from the place where the migrants move, stretches along the entire route of their movement and ends in places their ultimate destination. Having in mind the fact that previously and without any apparent reason about fifty thousand Kosovo Albanians went massively into emigration, using identical so-called Balkan route towards identical destinations, in the almost identical way, can rightly be suspected that behind everything stand the same organization, and that "Albanian refugee wave" was just a rehearsal for mass migrant waves from the Middle East and Africa. The refugee waves from the Middle East can be regarded from the aspect of voluntarism as compulsive, and from the aspect of organization as organized. In doing so, we must bear in mind that the assessment of the coercion of migration can only apply to the citizen's states where a war occur, and where people are clearly at risk. Among the migrants who cross over Serbia, there are also significant numbers of people who come from countries where there are no armed conflicts, and they can be considered as illegal migrant migrants rather than refugees (Dragisic, 2015: 376-377).

\section{Security approach to migration in context of terrorism and organized crime}

Migrations of the population, linked to other socially dangerous phenomena - terrorism, transcontinental organized crime, corruption - carry certain security challenges and risks for each country, regardless of whether they are the ultimate destination, transit or origin country. It should be kept in mind that the connection between migrations and harmful security phenomena is multidisciplinary and complex, it is often difficult to determine what the cause is and what the consequence is, and which the overall consequences of this connection are. Also, these phenomena cannot be viewed as isolated from other positive and negative social phenomena that affect them. 
The relationship between terrorism and various forms of migration is a complex one. The link between them, in general, is perceived in various spheres:

1. State terrorism as main cause of migration;

2. State failure as cause of terrorism and migration;

3. Non-state terrorism as cause of migration;

4. (Civil) War as major cause terrorism and migration;

5. Refugee camps and diasporas as causes (and targets) of terrorism;

6. Migrants as terrorists and terrorists as migrants;

7. Counter-terrorist operations as cause of forced migration (Schmid, 2016, 14-15)

This wide categorization represent some assumed connections where terrorism is said to cause migration or where migration is said to cause terrorism or where the two phenomena appear together, caused by a third element such as war or violence.

Although, as we can see, terrorism and migration can be connected in a many different ways, migration is often seen in the context of the threat of increasing terrorism in country of destination. The migration of millions of Muslims would significantly change the confessional image of Europe, and migrants in the coming period could be transformed into stakeholders of terrorist activities and be the tool of destabilization of European countries. Schmid argued that there a numerous ways on how migrant become terrorist and that is a complex process:

1. Migration in the Footsteps of the Prophet - a number of people migrated from Europe to Middle East, and those migrants turned into terrorists or at least joined a jihadist organization which engages in acts of terrorism Those of them who returned to Europe not out of disillusionment but with the intent to conduct attacks in their country of origin are returnee migrants turning terrorists, serving as a fifth column of the Islamic State in the West

2. Migration from one jihadist theatre of conflict to the next by professional Jihadists some jihadists move from one conflict to the other, e.g. from Afghanistan to Bosnia and from there to Chechnya and further on to Syria. They are wandering terrorists, partly because their country of origin would arrest them if they returned home and partly because jihad has become for them a way of life. Many of these foreign fighters might therefore become perpetual migrants, going from one jihadist hotspot to the next until they die.

3. Returning Foreign Terrorist Fighters - a number of migrants are returning migrants who have often been further radicalized in the conflict zones of jihad. When back home some of them are sleepers who sooner or later will get involved in plots

4. Economic migrants turning foreign terrorist fighters - for example The Islamic State province in Libya has plenty of enemies and only limited manpower. In order to boost its ranks, IS in Libya has begun abducting economic migrants from Sudan, Eritrea and West Africa en route through the Sahara to Europe.

5. Migrants' offspring radicalizing into terrorism - there is yet another way migrants can turn terrorists. If they are not fully integrated in host societies, they might develop resentment and with some that anger might become so strong that they - or more 


\section{Security}

likely, their children - turn against the host society. That has been one of the reasons why so many of the foreign fighters from Europe were the sons of immigrants (Schmid, 2016:41-46).

Schmid cited the widest framework for migrants to become a terrorist, but when it comes to migrants coming from the Middle East to Europe, it is unlikely that most of these ways will happen. Simeunovic believed that when it comes to the connection between migration and terrorism, it is not necessary to analyze only the connection between Islamic theorists and migrations. The future in Europe will certainly be marked by the rise of Islamist extremism, but its rise will be followed by another type of extremism, and that is right-wing, which will be a reaction on migration (Simeunovic, 2015:7).

Migrations are linked to organized crime in the context of the assumption that behind the wave of migrants lies organized crime that earns huge amounts of money on smuggling migrants. Clearly, this assumption implies that there should be a link between organized criminal groups and a corrupt European bureaucracy. Closing of borders and the so-called push-back policy resulted in the growth of a shadow economy and a market for smugglers who try to take people across borders illegally, risking their safety and breaking many national and international laws.

The danger of organized crime is mainly due to a distortion of the economic system and the principle of the rule of law. However, organized crime is increasingly becoming a political phenomenon and its holders have goal to conquer political power or to exercise greater influence Organized crime, in the conditions of weak and incomplete states, represents a serious security threat due to political aspirations that occur with the main organizers of criminal activities. Political aspirations of organized criminal activities are realized through corruption that takes over the most vulnerable economic branches and, in addition to legalizing unlawfully acquired money, prevents the economic basis of institutional strengthening of the state. The political parties, media, civil society, religious organizations, education and health systems become engulfed by the corruption and in this way a new form of totalitarianism is emerging, so-called oligarchy (Dragisic, 2010:88). So, smuggling of migrants and human trafficking is becoming a massive crime in the countries of the so-called first migrant destination, and at the same time the source of the vast illegal and non-taxable income. Their possible connection with European bureaucracy additionally increases this problem, making it to become a systemic problem of all European countries.

\section{Conclusion}

Human migration has taken place throughout history and has at times been considered as a threat, but more often as an opportunity. The perception of migration as a threat to national security has certainly been heightened in recent years, in part in response on two question: the rapid rise in the number of international migrants and especially of 'irregular' or 'illegal' 
migrants and the notion of 'the war on terrorism' and other so-called transnational threats have been linked to migration.

The research on the migration-security nexus tends are focus on a variety of aspects related to national security, understood as the protection and promotion of the well-being of the citizens and legal residents of the State. At the other hand, the debate on migration and security reflects the general trend in security studies to move beyond the national security perspective to embrace a human security perspective. Although the two perspectives on security and migration are often seen as contradictory, they can be brought together inter alia by adequate migration and border management policies, which take human security of migrants into account. Also, currently policies and practices in field of migration tend to focus on developed states of destination, it is necessary to broad this approach on the state of origin and transition.

Labelling migration as an issue a security threat has significant implications in term of laws, norms, policies and procedures, and can be used to justify harsh and restrictive policies. In the context of the process of securitizing migration we can notice a two strategies applied by developed countries: the control of migration flows through restrictive border policies is coupled with an effort to govern migration from a distance by using cooperative instruments.

It should be very careful in narrative about connection between terrorism and migration: a both of terms are securitized and very present in public discourse so the result should never be the impression that terrorist and migrant populations significantly overlap and that we are dealing with one and the same problem. Also, in context of connection between organized crime and migration, many state measures, such as closing the borders, have an impact on the increase of those who will misuse the situation of migrants and illegally import them into the desired countries. In this way, countries prevent a potential security problem in the form of migrants, in the sense of increasing the second, real problem in the form of organized crime. The existence of a fine balance between state policies and social reality in the context of migration should prevent the lesser of two evils principles.

\section{References}

1. A Psychological Perspective on the Current "Migration Crisis". The Society for the Psychological Study of Social Issues (SPSSI). Internet: https://www.spssi.org/index. $\mathrm{cfm}$ ?fuseaction=document.viewdocument $\&$ ID =3F28EB86AE4CA3BB2EE025BE0093BF0449E7256E585B742F418C59C78B1BF3198A419D9A5BFC2C3737450814D3839CB6. Access: 10.05.2018

2. About Migration Law - International Organization for Migration. Internet: www.iom.int/ about-migration-law, Acess: 18.05.1989.

3. Alexseev, M. (2006) Immigration Phobia and the Security Dilemma. Cambridge: Cambridge University Press.

4. Arsenovac, D. (2017). Demografski izazovi I migracije. Kultura polisa, 185-194.

5. Blagojevic, V., Milosavljevic, B. (2016) Politicko-pravni okvir savremenih migracija u Jugoisticnoj Evropi. Vojno delo, 75-93. 
6. Borjas, G. (1989). Economic Theory and International Migration. The International Migration Rewiew. 457-485.

7. Fakhoury, T. (2016) Tangled Connections between Migration and Security in the Wake of the Arab Uprisings: A European Perspective. Instituto Affari Internazionali, Working Paper 16.

8. Gajić, A. (2015) Uticaj regionalnih kriza na savremene prilike na Balkanu: geostrateške implikacije migrantske i ukrajinske krize. Kultura polisa, 11-29.

9. Gajic, A. (2016) Geopolitika sirijskih migracija i EU. Kultura polisa, br. 29,77-93.

10. Dragisic, Z. (2015) Organized Crime - The Way to Ochlocracy, Archibald Reiss Days, Belgrade: Academy of Criminalistic and Police Studies.

11. Dragišić, Z. (2015) Migracije kao bezbednosni problem. Srpska politicka misao, Vol. 50, No 4, 367-386.

12. Krewin, D. (2016) "Human Security, Civil Society and Migration". In: Human Security, Human Development, and Integration: Towards a Peaceful and Democratic Coexistence, Proceedings of the Fourth and Fifth International Forum on Migration and Peace, New York: Center for Migration Studies. Available at https://www.unocha. org/sites/dms/HSU/ Kerwin\%20statement.pdf (accessed on 29.05.2018).

13. Simeunovic, D. (2015) Migracije kao uzrok politickih anomalija u Evropi. Casopis za kriminalistiku i pravo. 1-17.

14. Schmid, A. (2016) Links between Terrorism and Migration: An Exploration. ICCT Research Paper. The International Centre for Counter-Terrorism - The Hague (ICCT).

15. The International Organization for Migration (IOM) - Key migration terms. Internet: https://www.iom.int/key-migration-terms, Access: 30.05.2018.

16. Stepic, M. (2016) Geopoliticki aspekti emigracione erupcije iz bliskoisticne "velike pukotine". Nacionalni interes, Vol. 25, No. 1, 19-41.

17. Thompson, C. (2013). Frontiers and Threats: Should Transnational Migration Be Considered a Security Issue?. Global Policy Journal. https://www.globalpolicyjournal.com/ blog/20/11/2013/frontiers-and-threats-should-transnational-migration-be-considered-security-issue. Access: 15.05.2018.

18. Wohlfeld M. (2014) Is Migration a Security Issue? In: Grech, 0. and Wohlfeld M. (Eds.). Migration in the Mediterranean: human rights, security and development perspectives. (pp. 61-77). Malta: University of Malta. 